\title{
The Effects of Gloss Modes on Chinese EFL Learners' Incidental Vocabulary Acquisition through Reading
}

\author{
Qin $\mathrm{Xu}^{1}$, Lili Yan \\ School of Foreign Language, Henan University of Technology, Zhengzhou 450001, China \\ ${ }^{1}$ Email: 1803691705@qq.com
}

Keywords: Gloss position, Textual enhancement, Reading, Incidental vocabulary acquisition.

Abstract: Vocabulary learning plays an indispensable and important role in foreign language learning. Incidental vocabulary acquisition is one of the common ways of vocabulary learning. Based on the previous studies, the present study attempts to investigate the effects of different gloss modes on Chinese EFL learners' incidental vocabulary acquisition through reading. Two important factors, i.e. gloss position (pre-text, post-text) and textual enhancement (with textual enhancement, without textual enhancement), as well as their interaction effects are examined. The results show that different gloss positions (pre-text, post-text) and textual enhancement (with textual enhancement, without textual enhancement) do not have significantly different effects on Chinese EFL learners' incidental vocabulary acquisition through reading and that no significant interaction effects between gloss position and textual enhancement have been found. Besides, students' performances on the immediate vocabulary tests and the delayed vocabulary tests are significantly correlated and delayed vocabulary retention is significantly weaker than immediate vocabulary retention. The current study sheds some light for English teachers and English textbook publishers in China.

Original article, Published date: 2018-05-29

DOI: 10.23977/aetp.2018.21002

ISSN: ISSN 2371-9397 (Print), ISSN 2371-9400 (Online)

https://www.clausiuspress.com/journal/AETP.html

\section{Introduction}

Vocabulary acquisition is regarded as one of the most important aspects of second language (L2) acquisition. The importance of the vocabulary has been recognized by more and more researchers 
especially in recent decades. Bowles (2004) asserts that without grammar very little can be conveyed, but without vocabulary can be conveyed.

The concept of "incidental vocabulary acquisition" by Nagy, Herman and Anderson in 1985, refers to the students accidentally learned words without focusing on remembering the words when they completed other tasks, such as reading, communication (Schmidt, 1994). A large number of studies have been carried out to investigate the effects of different factors on incidental vocabulary acquisition reading (Hulstijn et al., 1996; Paribakht \& Wesche, 1999; Day, Omura \& Hiramatsu, 1991; Xu, X., 2010; Knight, 1994; etc.). These factors include dictionary use, reoccurrence of unknown words, lexical glosses, context and so on. Among these factors, gloss arouses an increasing interest among researchers who attempt to explore the effects of glosses on reading comprehension and incidental vocabulary acquisition.

Gloss, defined as a short definition of unfamiliar words, has been found to facilitate reading comprehension, in that readers get more contextual cues while reading through given glosses. Many researchers (Jacobs et al., 1994; Hulstijn et al., 1996; Kamal \& Parisa, 2012; etc.) have also confirmed that glosses promote vocabulary growth as a by-product of reading.

Previous studies have generally proved that glosses can promote the incidental acquisition of words in reading. Recently, the research focus on glosses has shifted from whether glosses can aid vocabulary acquisition to which type of glosses is more effective. However, due to the diversity of gloss modes, there are still some deficiencies those researches. Although many studies have been devoted to investigating the effects of glosses on reading comprehension and incidental vocabulary acquisition, few studies have investigated the effects of gloss position on incidental vocabulary acquisition through reading. Another aspect of gloss that has not received enough attention is visual enhancement of the target word, which is also called textual enhancement or typographical input enhancement (White, 1998). Textual enhancement, according to Lee (2007: 90), "is an implicit technique of focus on form that uses visual enhancement methods, such as underlining, boldfacing, color-coding, italicizing, capitalizing or using different fonts".

Therefore, according to "The Noticing Hypothesis" put forward by Schmidt (1990) elaborates on the relationship between noticing and acquisition and "The Input Hypothesis" proposed by Krashen (1985) assumes that we acquire language by understanding, messages and that the more and the better messages are given the better the learning result would be, this research attempts to investigate the effects of gloss position(pre-text, post-text) and textual enhancement (with textual enhancement, without textual enhancement) on Chinese EFL learners' incidental vocabulary acquisition through reading by carrying out experiments

\section{Research Design and Methodology}

\subsection{Research Question}

This research, based on "The Noticing Hypothesis" and "The Input Hypothesis", aims to investigate the effects of gloss position and textual enhancement on incidental vocabulary acquisition through reading, the present study would address the specific questions stated as follows:

1) Do different gloss positions (pre-text, post-text) have different effects on Chinese EFL learners' incidental vocabulary acquisition through reading?

2) Does textual enhancement (with textual enhancement, without textual enhancement) have any effects on Chinese EFL learners' incidental vocabulary acquisition through reading?

3) Are there any interaction effects between gloss position and textual enhancement on Chinese EFL learners' incidental vocabulary acquisition through reading?

4) What is the relationship between Chinese EFL learners' performances on the immediate 
vocabulary tests and the delayed vocabulary tests?

\subsection{Subjects}

The subjects selected in this study were all sophomores majoring in English in the school of foreign languages of Henan University of Technology, from four randomly selected parallel classes. In order to ensure that four classes students' ability of English reading and vocabulary level has no obvious difference, all subjects' vocabulary level was tested and their English reading grades in freshman year were collected for reference. ANOVA data show that the vocabulary level of students in four classes is close $(\mathrm{F}=1.702, p=0.189>0.05)$ and there was no significant difference in reading level $(\mathrm{F}=0.364, p=0.689>0.05)$.

In order to select the difficult and appropriate target words, 22 students from one of the classes were given a predictive test before the experiment was officially started. The other three classes students (64 in total) participated in subsequent formal experiments and were randomly assigned to learning tasks with different gloss forms in each class. The final effective number of subjects was 73. In the data analysis process, four students were identified as non-English majors according to the name list, one student wrote nothing on the immediate vocabulary test. Thus these five students were eliminated from the data analysis, leaving 73 subjects in the end. The final number of subjects in each group is shown in the table 1.

Table 1 The Final Number of Subjects in Each Group

\begin{tabular}{cc}
\hline Group & Number of Subjects \\
\hline Pre-with & 17 \\
Pre-without & 18 \\
Post-with & 18 \\
Post-without & 20 \\
\hline
\end{tabular}

\subsection{Materials}

To ensure objectivity and validity of experimental materials, the following materials are employed, including reading texts, target words, glosses and reading comprehension questions. Krashen's input hypothesis points out that the difficulty of the ideal input material should be slightly higher than the current level of the learners. According to the Nation's (1990:134) research conclusion, the number of new words in the article should not exceed 5\% of the total number of materials. Therefore, the reading comprehension of TEM-4(Test for English Majors-4) of 2017, which the subjects never practiced before.

There are twelve target words in the present study and all of them are picked out through carefully designed procedures in the pilot study. It has been proved through the pilot study that they are unique twelve words that over $95 \%$ of the subjects had not known them before the experiment. In addition, each of the twelve target words appears in the text only once in four different gloss presentation forms. The glosses of the target words are bilingual. The reading text is followed by seven comprehension questions in the form of multiple choices. Besides, all the questions have no direct relations with the target words, but in order to answer the questions, subjects need to go over the paragraphs which contain the target words. Each question weighs one point, so the full score is 7 points. For example:

--How did the author feel about the treasure from the Atoch?

A. She was unconcerned about where the treasure came from

B. She was sad that she was unable to discover and salvage treasure

C. She was angry that treasure hunters were pillaging heritage 
D. She was glad that people can have a chance to see the treasure.

\subsection{Research Design}

The present study employs a $2 \times 2$ between subjects design. Specifically speaking, there are two independent variables: one is gloss position: pre-text and post-text; the other is textual enhancement: with textual enhancement and without textual enhancement. Thus there are four gloss presentation forms in total: Pre-with (pre-text glosses with textual enhancement), Pre-without (pre-text glosses without textual enhancement), Post-with (post-text glosses with textual enhancement), Post-without (post-text glosses without textual enhancement). The two dependent variables are the scores of the immediate vocabulary tests and the scores of the delayed vocabulary tests. The present study has gone through the following procedures: pilot study, reading treatments, post-tests (including one reading comprehension test, one immediate vocabulary test and one delayed vocabulary test, semi-structured interview) and data collection.

\subsection{Data Collection}

The author scored the reading comprehension tests, the immediate vocabulary tests and the delayed vocabulary tests according to the standard soon after the major experiment. For each subject, the scores on the three tests were put in parallel under his or her name. Then the subjects together with their three scores sorted into four Excel tables based on the form of the text they read: Pre-with, Pre-without, Post-with, Post-without.

\section{Results and Discussion}

The data obtained from the experiment in order to answer the research question of the present study, discuss the results and analyze the underlying reasons or influencing factors. The SPSS 16.0 software has been employed to conduct two-way analyses of Variance (ANOVA) with repeated measures on two factors test. The two factors are: Gloss position with two levels: pre-text and post-text; textual enhancement with two levels: with textual enhancement and without textual enhancement.

\subsection{Reliability of the vocabulary tests in the present study}

Before analyzing the data, the reliability of the vocabulary tests employed in this study should be verified in the first place.

Table 2 Reliability Statistics of the Vocabulary Tests

\begin{tabular}{ccc}
\hline Cronbach's Alpha & $\begin{array}{c}\text { Cronbach's Alpha Based } \\
\text { on Standardized Items }\end{array}$ & N of Items \\
\hline .595 & .581 & 12 \\
\hline
\end{tabular}

As can be seen from the table 2, the Cronbach's Alpha index is 0. 595. According to Leow (1997), the more the Cronbach's Alpha index approaches 1.00, the higher reliability the test has. Thus we can say that the vocabulary tests used in this study have a comparatively good reliability.

\subsection{The effects of different gloss positions on incidental vocabulary acquisition through reading}

The first question "Do different gloss positions (pre-text, post-text) have different effects on 
Chinese EFL learners' incidental vocabulary acquisition through reading?" will be addressed from two perspectives: immediate vocabulary retention and delayed vocabulary retention.

Table 3 Descriptive Statistics of Gloss Position in The Immediate Vocabulary Tests

\begin{tabular}{ccccc}
\hline Factor & Level & $\mathrm{N}$ & Mean & Std. Deviation \\
\hline Gloss & Pre-text & 34 & 8.4412 & 1.5801 \\
\cline { 2 - 5 } position & Post-text & 34 & 7.6765 & 2.7706 \\
\hline
\end{tabular}

Table 3 shows that the average score of the pre-text group outweighs that of the post-text group: $8.4412>7.6765$, which indicates that on the whole, subjects in the pre-text group have better performance than those in the post-text group. Students interviewed also expressed a preference to the pre- text glosses.

Table 4 Gloss Position Effects in the Immediate Vocabulary Tests

\begin{tabular}{cccccc}
\hline Source & $\begin{array}{c}\text { Type III Sum of } \\
\text { Squares }\end{array}$ & df & Mean Square & F & Sig. \\
\hline $\begin{array}{c}\text { Gloss } \\
\text { Position }\end{array}$ & 9.941 & 1 & 9.941 & 3.737 & 0.71 \\
\hline
\end{tabular}

Table 4 shows that $\mathrm{F}(1,6)=3.737,0.05<p=0.071<0.10, P$ stands for significance value, that is Sig. in the above table. According to Li (2010), if $p<0.05$, it can be reported that the statistical result has reached the significant level; if $p>0.10$, the statistical result has not reached the significant level; if $0.05 \leq p<0.10$, it can be reported that the statistical result is marginally significant or does not reach the significant level. Thus, from Table 4, it can be reported that the main effect of gloss position is marginally significant or does not reach the significant level. That is to say, in terms of immediate vocabulary retention, subjects tend to have better performance in reading texts with pre-text glosses than those with post-text glosses, but the tendency is not significant. This suggests that gloss position (pre-text, post-text) has no effects on incidental vocabulary acquisition through reading. The study by Zarei \& Hasani (2010) arrived at a similar conclusion, which found no significant difference upon vocabulary learning among either forms of glossing they examined: in the margin, in a footnote at the bottom of the page, or on an attached list.

Table 5 The effects of different gloss positions on delayed vocabulary retention

\begin{tabular}{ccccc}
\hline Factor & Level & N & Mean & Std. Deviation \\
\hline Gloss & Pre-text & 34 & 7.5588 & 1.9280 \\
\cline { 2 - 5 } Position & Post-text & 34 & 7.2059 & 1.7620 \\
\hline
\end{tabular}

Table 5 demonstrates that the average score of the pre-text group is higher than that of the post-text group: $7.558>7.2059$, which is congruent with the results in immediate vocabulary retention.

Table 6 Gloss Position Effects in the Delayed Vocabulary Tests

\begin{tabular}{cccccc}
\hline Source & $\begin{array}{c}\text { Type III Sum of } \\
\text { Squares }\end{array}$ & df & Mean Square & F & Sig. \\
\hline $\begin{array}{c}\text { Gloss } \\
\text { Position }\end{array}$ & 2.118 & 1 & 2.118 & .860 & .367 \\
\hline
\end{tabular}

From Table 6, we can see that the main effect of gloss position is not significant: $F(1,16)=$ $0.860, p=0.367>0.10$. That is to say, different gloss positions (Pre-text, post-text) do not have significantly different effects on incidental vocabulary acquisition in terms of delayed vocabulary 
retention. Ko(2012)'s study investigated the effect of L1 glosses, L2 glosses as well as no glosses on L2 vocabulary learning. Ko indicated the existence of significant time effects in L1 and L2 gloss conditions over time but not in the no-gloss condition. The similarity between the immediate vocabulary tests and the delayed vocabulary tests is in accordance with the result of the present study, though the independent variables of Ko's study are different from those of the present one.

\subsection{The effects of textual enhancement on incidental vocabulary acquisition through reading}

The question whether textual enhancement (with textual enhancement, without textual enhancement) has any effects on Chinese EFL learners' incidental vocabulary acquisition through reading is to be explored in this section from the perspectives of immediate vocabulary retention as well as delayed vocabulary retention.

Table 7 Descriptive Statistics of Textual Enhancement in the Immediate Vocabulary Tests

\begin{tabular}{ccccc}
\hline Factor & Level & $\mathrm{N}$ & Mean & $\begin{array}{c}\text { Std. } \\
\text { Deviation }\end{array}$ \\
\hline $\begin{array}{c}\text { Textual } \\
\text { enhancement }\end{array}$ & With-textual- enhancement & 34 & 8.3235 & 1.5286 \\
\cline { 2 - 5 } & Without-textual-enhancement & 34 & 7.7941 & 2.1390 \\
\hline
\end{tabular}

Table 7 reveals that the mean of the with-textual-enhancement group is higher than that of without-textual-enhancement: 8.3235>7.7941. Students interviewed also had a favor in texts with textual enhancement.

Table 8 Textual Enhancement Effects in the Immediate Vocabulary Tests

\begin{tabular}{cccccc}
\hline Source & $\begin{array}{c}\text { Type III Sum of } \\
\text { Squares }\end{array}$ & df & $\begin{array}{c}\text { Mean } \\
\text { Square }\end{array}$ & F & Sig. \\
\hline $\begin{array}{c}\text { Textual } \\
\text { Enhanceme } \\
\text { nt }\end{array}$ & 4.765 & 1 & 4.765 & 1.344 & .263 \\
\hline
\end{tabular}

Table 8 shows $F(1,16)=1.344, p=0.263>0.10$, indicating that the main effect of textual enhancement is not significant. In other words, textual enhancement does not have significantly different effects on immediate vocabulary retention. The Input Hypothesis raised by Krashen(1985) suggests that the more and the better messages are given, better the learning result would be. Textual enhancement, that is bolding the target words in this study, may not be powerful enough to induce more incidental vocabulary acquisition, so participants who read texts with textual enhancement do not show better performance upon vocabulary acquisition.

Table 9 Descriptive Statistics of Textual Enhancement in the Delayed Vocabulary Tests

\begin{tabular}{ccccc}
\hline Factor & Level & $\mathrm{N}$ & Mean & $\begin{array}{c}\text { Std. } \\
\text { Deviation }\end{array}$ \\
\hline $\begin{array}{c}\text { Textual } \\
\text { enhancement }\end{array}$ & With-textual-enhancement & 34 & 7.500 & 1.7193 \\
\cline { 2 - 5 } & Without-textual-enhancement & 34 & 7.2647 & 1.9750 \\
\hline
\end{tabular}

It can be seen from Table 9 that the mean of the with-textual-enhancement group is higher than that of without-textual-enhancement: $7.500>7.2647$, which is consistent with that in the immediate vocabulary tests. 
Table 10 Textual Enhancement Effects in the Delayed Vocabulary Tests

\begin{tabular}{cccccc}
\hline Source & $\begin{array}{c}\text { Type III Sum of } \\
\text { Squares }\end{array}$ & df & Mean Square & F & Sig. \\
\hline $\begin{array}{c}\text { Textual } \\
\text { Enhancement }\end{array}$ & .941 & 1 & .941 & .205 & .657 \\
\hline
\end{tabular}

From Table 10, F $(1,16)=0.205, p=0.657>0.10$ from Table 3.9 shows that the main effect of textual enhancement is not significant. Namely, textual enhancement has no significant effects on delayed vocabulary retention. The result also accords with that of immediate vocabulary retention.

\subsection{The interaction effects of gloss position and textual enhancement on incidental vocabulary acquisition through reading}

In this section, immediate vocabulary retention and delayed vocabulary retention will be probed into to investigate the interaction effects of gloss position and textual enhancement on incidental vocabulary acquisition through reading.

Table 11 Descriptive Statistics of the Four Groups in the Immediate Vocabulary Tests

\begin{tabular}{cccc}
\hline Group & Mean & Std. Deviation & $\mathrm{N}$ \\
\hline Pre-with & 8.4706 & 1.4500 & 17 \\
Pre-without & 8.4118 & 2.1709 & 17 \\
Post-with & 8.1765 & 1.5806 & 17 \\
Post-without & 7.1765 & 1.9170 & 17 \\
\hline
\end{tabular}

From Table 11, we can see that the average score of the Post-without group is the lowest and that of the Pre-with group is the highest: $7.1765<8.1765<8.4118<8.4706$. The results are consistent with those presented before. Subjects interviewed also showed a preference for the reading text with pre-text glosses and textual enhancement.

Table 12 Interaction Effects in the Immediate Vocabulary Tests

\begin{tabular}{cccccc}
\hline Source & $\begin{array}{c}\text { Type III Sum of } \\
\text { Squares }\end{array}$ & df & $\begin{array}{c}\text { Mean } \\
\text { Square }\end{array}$ & F & Sig. \\
\hline $\begin{array}{c}\text { Gloss Position* } \\
\text { Textual } \\
\text { Enhancement }\end{array}$ & 3.765 & 1 & 3.765 & 1.377 & .258 \\
\hline
\end{tabular}

Table 12 reveals that the interaction effect of gloss position and textual enhancement is not significant: $\mathrm{F}(1,16)=1.377, p=0.258>0.10$. The result is congruent with that of Wu, Zhou et al.'s study (2012), which also did not discover significant interaction effect of the two factors. As it has been testified that neither gloss position (pre-text, post-text) nor textual enhancement is a significant influencing factor in incidental vocabulary acquisition through reading, it is easily understandable why there are no significant interaction effects of gloss position and textual enhancement.

Table 13 Descriptive Statistics of the Four Groups in the Delayed Vocabulary Tests

\begin{tabular}{cccc}
\hline Group & Mean & Std. Deviation & $\mathrm{N}$ \\
\hline Pre-with & 7.5882 & 6.4898 & 17 \\
Pre-without & 7.5294 & 9.1780 & 17 \\
Post-with & 7.4118 & 7.6235 & 17 \\
Post-without & 7.0000 & 6.7823 & 17 \\
\hline
\end{tabular}


Table 13 demonstrates similar results with Table 11. To be specific, in terms of delayed retention, the average score of the four groups ranks this way: Pre-with> Pre-without> Post-with> Post-without. The results are similar to that in the immediate vocabulary tests.

Table 14 Interaction Effects in the Delayed Vocabulary Tests

\begin{tabular}{cccccc}
\hline Source & $\begin{array}{c}\text { Type III Sum of } \\
\text { Squares }\end{array}$ & df & Mean Square & F & Sig. \\
\hline $\begin{array}{c}\text { Gloss Position* } \\
\text { Textual Enhancement }\end{array}$ & .529 & 1 & .529 & .157 & .697 \\
\hline
\end{tabular}

Table 14 shows that the interaction effect of gloss position and textual enhancement is not significant: $\mathrm{F}(1,16)=0.157, p=0.697>0.10$. In other words, there are no interaction effects of gloss position (Pre-text, post-text) and textual enhancement on delayed vocabulary retention. The results are the same as those in the immediate vocabulary tests.

\subsection{Correlation between the immediate vocabulary tests and the delayed vocabulary tests}

Table 15 presents the descriptive statistics of correlation between the immediate vocabulary tests and the delayed vocabulary tests.

Table 15 Descriptive Statistics of Correlation between the Immediate Vocabulary Tests and the Delayed Vocabulary Tests

\begin{tabular}{clcc}
\hline Test & & Immediate & Delayed \\
\hline \multirow{3}{*}{ Immediate } & Pearson Correlation & 1 & $.492^{* *}$ \\
\cline { 2 - 4 } & Sig.(2-tailed) & & .000 \\
\cline { 2 - 4 } Delayed & $\mathrm{N}$ & 68 & 68 \\
\cline { 2 - 4 } & Pearson Correlation & $.492^{* *}$ & 1 \\
\cline { 2 - 4 } & Sig. (2-tailed) & .000 & \\
\cline { 2 - 4 } & $\mathrm{N}$ & 68 & 68 \\
\hline \multirow{2*}{*}{ Con }
\end{tabular}

**. Correlation is significant at the 0.01 level(2-tailed)

From Table 15, we can say that the immediate vocabulary tests and the delayed vocabulary tests are significantly correlated, $\mathrm{r}=0.492, \mathrm{p}<0.01$. In other words, better immediate vocabulary retention leads to comparatively better delayed vocabulary retention.

The table below displays the paired samples statistics of the immediate vocabulary tests and the delayed vocabulary tests.

Table 16 Paired Samples Statistics of the Immediate Vocabulary Tests and the Delayed Vocabulary Tests

\begin{tabular}{|c|c|c|c|c|c|}
\hline & & Mean & $\mathrm{N}$ & Std. Deviation & Std. Error Mean \\
\hline Pair & Immediate & 8.06 & 68 & 1.892 & .229 \\
\hline 1 & Delayed & 7.38 & 68 & 1.869 & 227 \\
\hline
\end{tabular}

Table 16 shows the average score (Mean) and standard deviation (Std. Deviation) of the two tests. The mean of the immediate vocabulary test is higher than that of the delayed vocabulary est:8.06 > 7.38. 
Table 17 Paired Samples Test of the Immediate Vocabulary Tests and the Delayed Vocabulary Tests

\begin{tabular}{|c|c|c|c|c|c|c|c|c|c|}
\hline \multicolumn{7}{|c|}{ Paired Difference } & \multirow[t]{3}{*}{$\mathrm{t}$} & \multirow[t]{3}{*}{$\mathrm{df}$} & \multirow[t]{3}{*}{$\begin{array}{c}\text { Sig. } \\
\text { (2-tailed) }\end{array}$} \\
\hline & & \multirow[t]{2}{*}{ Mean } & \multirow{2}{*}{$\begin{array}{c}\text { Std. } \\
\text { Deviation }\end{array}$} & \multirow{2}{*}{$\begin{array}{l}\text { Std. } \\
\text { Error } \\
\text { Mean }\end{array}$} & \multicolumn{2}{|c|}{$\begin{array}{l}95 \% \text { Confidence } \\
\text { Interval of the } \\
\text { Difference }\end{array}$} & & & \\
\hline & & & & & Lower & Upper & & & \\
\hline Pair 1 & $\begin{array}{c}\text { Immediate- } \\
\text { delayed }\end{array}$ & .676 & 896 & 230 & 218 & 1.135 & 2.942 & 67 & .004 \\
\hline
\end{tabular}

Table 17 indicates that the subjects' scores of the immediate vocabulary test and the delayed vocabulary test are significantly different: $\mathrm{t}(67)=2.942, \mathrm{p}=0.004<0.01$. The result is in consistent with that of Ko (2012) who also found that the overall mean score dropped significantly on the delayed vocabulary test.

\section{Conclusion}

This study makes a tentative attempt to explore the effects of gloss position (Pre-text, post-text) and textual enhancement on Chinese EFL learners' incidental vocabulary acquisition through reading from two perspectives: immediate vocabulary retention and delayed vocabulary retention. Each factor has two levels, resulting in four groups: pre-with, pre-without, post-with, post-without. It an be concluded that this study discovers no superior advantage of one over another between pre-text glosses and post-text glosses whether in reading texts with textual enhancement or without textual enhancement.

First of all, different glosses positions (pre-text, post-text) do not have significantly different effects on Chinese EFL learners' incidental vocabulary acquisition through reading. Secondly, textual enhancement (with textual enhancement, without textual enhancement) does not have significant effects on Chinese EFL learners' incidental vocabulary acquisition through reading. Third, there are no significant interaction effects between gloss position (pre- text, post-text) and textual enhancement on Chinese EFL learners' incidental vocabulary acquisition through reading. Lastly, scores of the immediate vocabulary tests and the delayed vocabulary tests are significantly correlated and delayed vocabulary retention is significantly weaker than immediate vocabulary retention.

This study has great theoretical and practical significance on the effects of glosses on incidental vocabulary acquisition through reading for both teaching and learning. However, there also are some limitations of this study. Both the number of subjects is not large enough and the proportion of the number of the target words to the number of words of the whole text is not big enough are the limitations of this study which should be improved to become the well-designed experiment to demonstrate more accurate conclusions.

\section{References}

[1] Bowles, M. A. (2004). L2 Glossing: To CALL or not Call, Hispania, 87(3):541-552.

[2] Day, R. R., C. Omura \& M. Hiramatsu (1991). Incidental EFL Vocabulary Learning and Reading, Reading in a Foreign Language, 7: 541-551.

[3] Hulstijn, J., M. Holander \& T. Greidanus (1996). Incidental Vocabulary Learning by Advanced Foreign Language Students: The Influence of Marginal Glosses, Dictionary Use, and Reoccurrence of Unknown Words, Modern Language Journal, 80(3): 327-339. 
[4] Jacobs. G. M., P. Dufon \& F. C. Hong (1994). L1 and L2 Vocabulary Glosses in L2 Reading Passages: Their Effectiveness for Increasing Comprehension and Vocabulary Knowledge, Journal of Research in Reading, 17 (1):19-28.

[5] Kamal, H. S.\& P. R. Parisa (2012). On the Impact of Lexical Glossing on Receptive Skills of EFL Learners, World Applied Sciences Journal, 18 (4): 502-509.

[6] Knight, S. (1994). Dictionary Use while Reading: The Effects on Comprehension and Vocabulary Acquisition for Students of Different Verbal Abilities, The Modern Language Journal, 78: 285-299.

[7] Ko, Hee, Myong (2012). Glossing and Second Language Vocabulary Learning, TESOL Quarterly 46: 56-79.

[8] Krashen, S. (1985). The Input Hypothesis: Issues and Implication. London: Longman.

[9] Lee, S. K. (2007). Effects of Textual Enhancement and Topic Familiarity on Korean EFL Students' Reading Comprehension and Learning of Passive Form, Language Learning 57 (1): 87-11

[10] Leow. R. (1997). The Effects of Input Enhancement and Teat Length on Adult L2 Readers' Comprehension and Intake in Second Language Acquisition, Applied Language Learning 8: 151-182.

[11] Nation. I. S. P.(1990). Teaching and Learning Vocabulary. New York: Newbury House.

[12] Paribakht, T.S. \& M. Wesche (1999). Reading and "Incidental" L2 Vocabulary Acquisition, Studies in Second Language Acquisition, 21:195-224.

[13] Schmidt, R. W. (1990). The Role of Consciousness in Second Language Learning, Applied Linguistics, 11:129-158.

[14] Schmidt, R. (1994). Implicit learning and the cognitive unconscious of artificial grammars and SLA [A]. In N. C. Ellis, (eds. ). Implicit and Explicit Learning of Languages[C]. London: Academic Press, 165-210.

[15] White, J. (1998). Getting the Learners' Attention: A Typographical Input Enhancement Study. In C. Doughty \& J. Williams (eds.). Focus on Form in Classroom Second Language Acquisition. Cambridge: Cambridge University Press, 85-113.

[16] Wu Wei, Zhou Rong \& Xu Hong (2012). The effect of glosses presentation on the understanding of second language reading and the incidental acquisition of vocabulary, Foreign Language and Literature Studies, 114 (4):267-273

[17] Xu, Xiaohui. (2010). The Effects of Glosses on Incidental Vocabulary Acquisition in Reading, Journal of Language Teaching and Research, 1:117-120.

[18] Zarei. A. A. \& S. Hasani (2010). The Effects of Glossing Conventions on L2 Vocabulary Recognition and Production. The Journal of Teaching Language Skills 3(2):209-233. 